\title{
Pain model and fuzzy logic patient-controlled analgesia in shock-wave lithotripsy
}

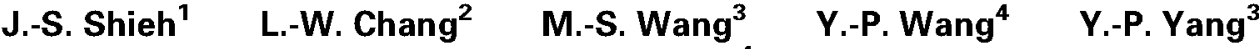 \\ W.-Z. Sun ${ }^{4}$ \\ ${ }^{1}$ Department of Mechanical Engineering, Yuan Ze University, Taiwan \\ ${ }^{2}$ Institute of Biomedical Engineering, National Taiwan University, Taiwan \\ ${ }^{3}$ Department of Mechnical Engineering, National Taiwan University, Taiwan \\ ${ }^{4}$ Department of Anaesthesiology, College of Medicine, National Taiwan University, Taiwan
}

\begin{abstract}
Pain control in conscious patients was investigated using a push-button, demand-driven supply of drugs. A fuzzy logic patient-controlled analgesia (PCA) algorithm was compared with a conventional algorithm, for alfentanil administration in extracorporeal shock-wave lithotripsy. The conventional PCA algorithm used an initial dose of $0.25 \mathrm{mg}$, a fixed infusion rate of $60 \mathrm{mg} \mathrm{h}^{-1}$ and a fixed bolus size of $0.2 \mathrm{mg}$ with a $1 \mathrm{~min}$ lockout. The fuzzy logic PCA algorithm used an initial dose of $0.25 \mathrm{mg}$, a changeable infusion rate and a bolus size of 0.1 or $0.05 \mathrm{mg}$. The infusion rate was adjusted according to a look-up table that accepted the button-pressing history over the last three lockout intervals. The look-up table was designed using fuzzy logic. The bolus size was adjusted according to the button-pressing history over the past two lockout intervals. Twelve patients were treated using conventional PCA, and thirteen were treated with PCA +fuzzy logic control (FLC). PCA + FLC patients consumed 45\% less drug. Also, PCA + FLC patients had a mean delivery/demand ratio of $82 \%$, compared with $60 \%$ in conventional PCA. When the pain intensity scale was analysed, PCA + FLC patients had acceptable pain intensity at $62 \%$, compared with $44 \%$ in conventional PCA.
\end{abstract}

Keywords-Pain model, Pain intensity scale, Patient-controlled analgesia, Fuzzy logic control, Extracorporeal shock-wave lithotripsy

Med. Biol. Eng. Comput., 2002, 40, 128-136

\section{Introduction}

PAIN CONTROL is a challenging topic, as there has not been any distinct physiological sign used for objective pain detection. In reality, patient controlled analgesia (PCA) has been applied to pain control for many years and has been accepted as a valuable method for post-operative pain management.

However, conventional PCA has a number of limitations. First, there is often uncertainty concerning the optimum bolus size (OWEN et al., 1995; Love et al., 1996). Bolus sizes are generally tailored for the patient population most sensitive to analgesics, and yet patient requirements for adequate analgesia can vary up to ten-fold because of the huge variation in drug sensitivity for each patient (WOODHOUSE and MATHER, 1997). Secondly, the technology of PCA devices does not easily accommodate higher analgesic requirements in the immediate post-operative period (LYNCH et al., 1998; KATZ et al., 1996).

Manual adjustment of the PCA prescription is currently the only method by which higher initial analgesic requirements can

Correspondence should be addressed to $\operatorname{Dr}$ L.-W. Chang email: bmech/w@ccms.ntu.edu.tw

Paper received 8 December 2000 and in final form 29 October 2001 MBEC online number: 20023640

(C) IFMBE: 2002 be accommodated. Hence, we have developed a fuzzy logic control (FLC) applied in the PCA to the relief of intra-operative pain that adjusts both the bolus dose and the background infusion rate of analgesic, depending on how often the patient presses the button.

Fuzzy logic control not only provides a simple way to create a non-linear controller but also accommodates control rules that are easily understood and therefore readily modifiable when discussed with experts (i.e. anaesthetists).

LINKENS and MAHFOUF (1998) published an early study on fuzzy control of muscle relaxation via simulation. Also, CAROLLO et al. (1993) published their simulation results on a fuzzy controller of post-operative pain. Only, recently has this been implemented in clinical trials (MASON et al., 1996; $1997 a$; $b$; Ross et al., 1997) of a fuzzy controller for atracurium-induced neuromuscular block. With our experience in applying fuzzy logic control to muscle relaxation (SHIEH et al., $1996 ; 1997)$, successful clinical results have encouraged us to look into this fuzzy logic PCA system for pain intensity control in a therapeutic procedure.

Although they might not like to admit it, anaesthetists use 'rules of thumb' when managing patients. An anaesthetist probably uses a rule of thumb to determine the extent and direction of adjustments. That the anaesthetist uses imprecise, personal rules does not prevent the provision of a safe and effective anaesthetic. 
Consider a rule of thumb such as 'If the pain is greater than the patient's expectation by a large amount and the pain is moving towards the big pain but only slowly, then set the alfentanil infusion rate to a high level'. This rule contains imprecise terms such as 'a large amount', 'slowly' and 'a high level', terms that are difficult to express and manipulate in a computer. Humans have no difficulty with such imprecise information, but it is an obstacle to exploiting an expert's knowledge in a computer system, simply because there is no language to describe imprecise data in a way that a computer understands (YING et al., 1988).

The key to this problem was described in an article by Lofti Zadeh who introduced 'fuzzy sets' to deal with imprecise, qualitative terms such as low, medium and high (ZADEH, 1965). A fuzzy logic control was then designed with control rules that are easy for users to understand and therefore simple for users to modify. In this research, a fuzzy logic pain controller using the fuzzy logic and rule of thumb concepts has been designed to control patient pain intensity in an easy, efficient and safe manner during an extracorporeal shock-wave lithotripsy (ESWL) operation.

ESWL is a surgical procedure to remove calculi so that urinary obstruction or infection can be prevented or cured. Calculi are hard, pebble-like stones formed within the body, particularly in the gall bladder (i.e. gallstones) or anywhere in the urinary tract (i.e. cystolithiasis). Calculi in the urinary tract are commonly composed of calcium oxalate and are usually visible on X-ray examination. Most of these stones cause pain, whether sited in the kidney, urethra, or bladder; stones passing down a duct (such as the urethra) cause severe, colicky pain.

In ESWL, used for destroying calculi in the upper urinary tract and gallstones, shock waves are generated and transmitted by an external power source. The specialised machine used in ESWL consists of a sophisticated radiological system to localise the stone accurately by biplanar X-ray or ultrasound and a shock head or transducer to produce and focus the energy source.

ESWL was chosen as a procedure when we performed this research to study the application of a fuzzy logic PCA algorithm to acute pain control. Pain during ESWL has been treated successfully with epidural or general anaesthesia, and ESWL has been performed on a large number of patients since this innovative technology was introduced in 1980. In addition, modern, second-generation lithotriptors offer immersion-free treatment and decreased shock wave-induced pain, owing to the use of less shock-wave energy, and can avoid constant pain in patients. These systems are especially suitable for simplified analgesic techniques, and many such methods have been suggested (SCHELLING et al., 1989; 1996; MONK et al., 1994).

Current pain control of the ESWL operation is as follows. When the patient enters the operation room for ESWL treatment, the urologist and technician first check the X-ray photograph of the patient. Secondly, the technician calibrates the position of the stones (i.e. calculi) using the X-ray machine and then spreads jelly on the head of the ESWL system. Thirdly, the nurse anaesthetist measures the clinical signs of the patient (i.e. $\mathrm{SAP}, \mathrm{HR}, \mathrm{SpO}_{2}$ and RR).

After these three steps, the patient undergoes ESWL treatment. However, if the patient has any pain during the therapy, he or she can raise a hand, and the technician stops the ESWL operation. Then, the nurse anaesthetist enters the operation room to ask the patient's conditions related to pain intensity. If the patient complains of pain, the nurse anaesthetist will give a bolus dose of opioid to suppress the pain intensity. Hence, the current method is time-consuming, and patients suffer pain during the operation.
In the search for more comfortable pain therapy and to save operation time, the PCA is thought to be a good, suitable solution. The PCA is controlled by the patient pushing a button to administer a small dose of pain killer drugs at fixed intervals. However, the PCA still produces some clinical side effects, such as nausea, dizziness and vomiting.

According to previous clinical trials using fuzzy logic technology, we propose our hypothesis in this paper that a fuzzy logic PCA algorithm (i.e. PCA + FLC) would reduce the amount of drug consumption, and the patient's satisfaction would be increased when compared with the conventional PCA method. Also, a new approach to analyse the pain intensity scale using a pharmacokinetic model combined with either PCA + FLC or the PCA method is presented.

\section{Control system design}

Fig. 1 shows the PCA and the PCA + FLC control structure. The current PCA method provides the patient with a pain driven button that activates the pump to administer a bolus dose of analgesic at a fixed time interval (lockout time). However, the PCA + FLC algorithm uses a small bolus size and a changeable infusion rate. The infusion rate is adjusted according to a look-up table that accepts the button-pressing history over the last three lockout intervals. The look-up table is designed using fuzzy logic. The bolus size is adjusted according to the button-pressing history over the last two lockout intervals.

Control rules, membership functions and defuzzification are three essential elements in fuzzy logic control. To perform fuzzy inference and describe the pain control system, we chose two inputs, which were the pain intensity (Pain_Intensity) and the change of pain intensity ( $\Delta$ Pain_Intensity), and one output, which was the change in alfentanil infusion rate ( $\Delta F$ low_Rate).

To fuzzify the inputs and output, the pain intensity was divided into three levels: big pain (BP), small pain (SP) and zero pain (ZP). There is no negative fuzzy set because of the nonfeasible nature for pain intensity. The change in pain intensity was divided into five levels: negative big (NB), negative small $(\mathrm{NS})$, zero (ZR), positive small (PS) and positive big (PB). Also, the change in alfentanil infusion rate was divided into five levels: big decrease (BD), small decrease (SD), zero (ZO), small increase (SI) and big increase (BI).

According to anaesthesiologists' experience, nine rules were developed to control the pain control system, as shown in Table 1 . The change in pain intensity is defined as the current pain intensity minus the previous pain intensity. Moreover, because of the non-feasible nature of a negative
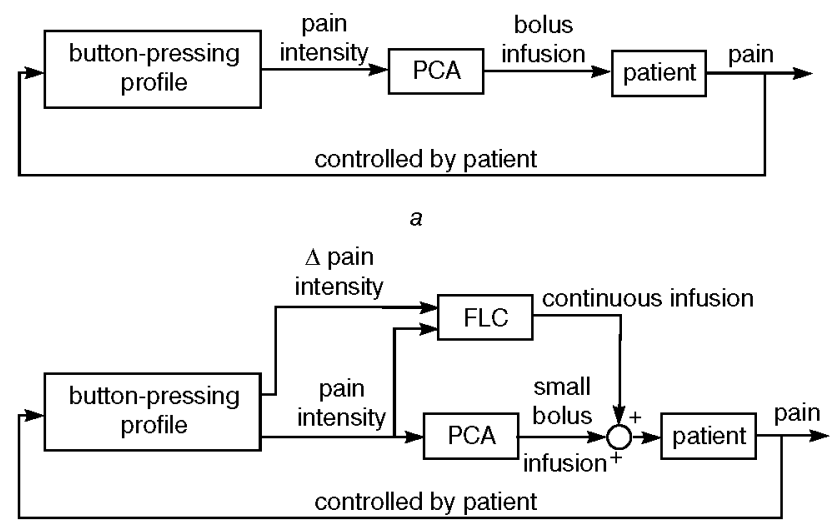

$b$

Fig. 1 Block diagram of control system to administer alfentanil infusion depending on button-pressing profile of patient. (a) Conventional PCA controller; (b) PCA + FLC controller 
Table 1 Anaesthesiologist's rule-base for controlling pain intensity system using change of alfentanil infusion rate (see text for details)

\begin{tabular}{lccc}
\hline & \multicolumn{3}{c}{ Pain_Intensity } \\
\cline { 2 - 4 }$\Delta$ Pain_Intensity & BP & SP & ZP \\
\hline NB & & & BD \\
NS & & SD & SD \\
ZR & BI & ZO & ZO \\
PS & SI & SI & \\
PB & ZO & & \\
\hline
\end{tabular}
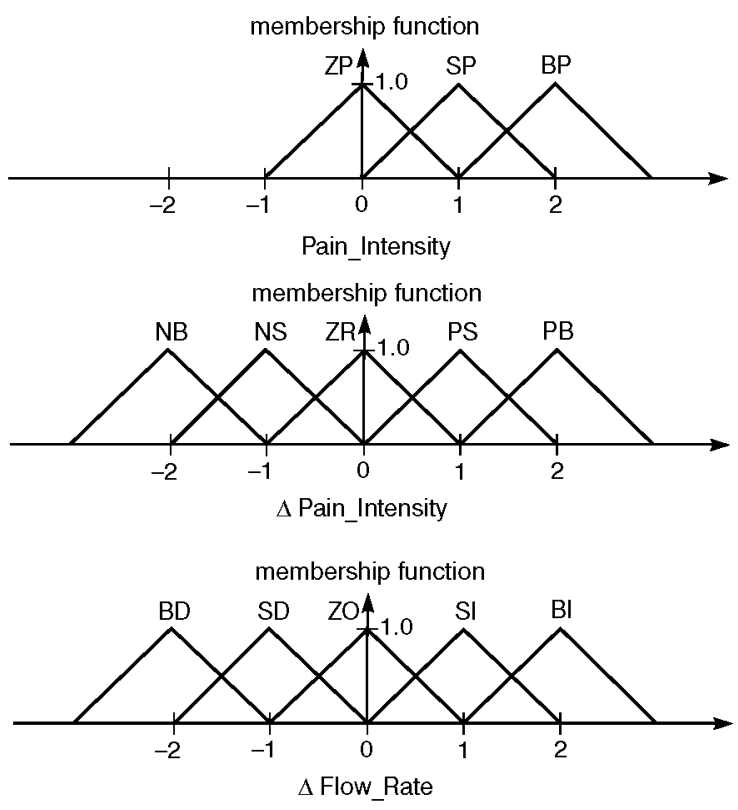

Fig. 2 Membership functions of two inputs and one output

fuzzy set for pain intensity, there exist six empty spaces in Table 1, where it is impossible to have rules. There are many shapes (DOMBI, 1990; KOUATLI and JONES, 1991) of possible membership functions, such as triangle, trapezoid etc., that can be used in the fuzzy logic controller. For simplicity and popularity, a triangle shape is used, and a $25 \%$ overlap for contiguous fuzzy sets is reckoned (KOSKO, 1991), as shown in Fig. 2, for two inputs (Pain_Intensity and $\Delta$ Pain_Intensity) and one output ( $\Delta$ Flow_Rate).

When Pain_Intensity and $\Delta$ Pain_Intensity have been obtained, their quantified levels should be determined. There are two main procedures for the implication and inference of rules that are used in most controllers, the max-min and maxproduct procedures (DOMBI, 1990). The former method was adopted in this study. Meanwhile, the values of membership functions can be obtained from Fig. 2. Each rule has a different grade of contribution for these inputs. There are two main methods for defuzzification procedures, mean of maximum (MOM) and centre of area (COA) (BRAAE and RUTHERFORD, 1978). The latter procedure has been adopted because it gives smoother signals. Therefore the equation of the COA procedure for the control input can be written as follows (LI and LAU, 1989):

$$
I=\frac{\sum_{1}^{n}\left(M_{n} \times U_{n}\right)}{\sum_{1}^{n} M_{n}}
$$

where $M$ is the membership function, $U$ is the universe of discourse, and $n$ is the number of rules.

*Equipped by Siemens Nixdorf
Table 2 Look-up table for controlling pain intensity system using change of alfentanil infusion rate

\begin{tabular}{lccc}
\hline & \multicolumn{3}{c}{ Pain_Intensity } \\
\cline { 2 - 4 }$\Delta$ Pain_Intensity & $\mathrm{BP}(+2)^{*}$ & $\mathrm{SP}(+1)^{*}$ & $\mathrm{ZP}(0)^{*}$ \\
\hline $\mathrm{NB}(-2)^{\dagger}$ & & & -1.50 \\
$\mathrm{NS}(-1)^{\dagger}$ & & -0.43 & -0.83 \\
$\mathrm{ZR}(0)^{\dagger}$ & 0.83 & 0.25 & -0.17 \\
$\mathrm{PS}(+1)^{\dagger}$ & 0.83 & 0.71 & \\
$\mathrm{~PB}(+2)^{\dagger}$ & 0.50 & & \\
\hline
\end{tabular}

* Numbers in brackets indicate definition of pain intensity

$\uparrow$ Numbers in brackets are result of subtracting previous Pain_Intensity from current Pain_Intensity

Thus combining all rules produces a look-up table, as shown in Table 2. As the output fuzzy set of the controller is defuzzified, it can be sent to the process after being scaled from normalised values to real values. In this study, the scaling factor for this output was chosen to be 8.58 ; this choice was aimed at providing a sensitive controller to control the pain control system accurately (LINKENS and ABBOD, 1992).

To obtain the button-pressing profile of the patient using the fuzzy logic method, the big pain (BP), small pain (SP) and zero pain $(\mathrm{ZP})$ levels of pain intensity were defined as follows:

(a) BP: a button has been pushed in both the previous and current lockout intervals

(b) SP: a button has been pushed in the current lockout interval and not in the previous lockout interval

(c) ZO: a button is pushed in neither previous nor current lockout intervals.

According to the aforementioned fuzzy logic theory, a lookup table can be obtained, as shown in Table 2, to administer the alfentanil. The drug infusion parameters are shown in Table 3 and can be compared with those in Table 4 that have been commonly used in current PCA therapy.

The conventional PCA algorithm uses an initial dose of $0.25 \mathrm{mg}$, a fixed infusion rate of $60 \mathrm{mg} \mathrm{h}^{-1}$ and a fixed bolus size of $0.2 \mathrm{mg}$ with a $1 \mathrm{~min}$ lockout. The PCA + FLC algorithm uses an initial dose of $0.25 \mathrm{mg}$, a changeable infusion rate and a bolus size of 0.1 or $0.05 \mathrm{mg}$. The infusion rate is adjusted according to a look-up table that accepts the button-pressing

Table 3 Alfentanil parameters of PCA $F L C$ therapy

\begin{tabular}{lc}
\hline Analgesic drug & Alfentanil \\
\hline Concentration $\mathrm{mg} \mathrm{ml}^{-1}$ & 0.1 \\
Initial dose, $\mathrm{ml}$ & 2.5 \\
Bolus dose depending & \\
$\quad$ on button-pressing, $\mathrm{ml}$ & 1 \\
$\mathrm{BP}$ & 0.5 \\
$\mathrm{SP}$ & 1 \\
Lockout time, min & changeable depending on \\
Continuous infusion rate, $\mathrm{ml} \mathrm{h}^{-1}$ & button-pressing profile \\
&
\end{tabular}

Table 4 Alfentanil parameters of current PCA therapy

\begin{tabular}{lc}
\hline Analgesic drug & Alfentanil \\
\hline Concentration, $\mathrm{mg} \mathrm{ml}^{-1}$ & 0.5 \\
Initial dose, $\mathrm{ml}$ & 0.5 \\
Bolus dose, $\mathrm{ml}$ & 0.4 \\
Lockout time, $\mathrm{min}$ & 1 \\
Infusion rate, $\mathrm{ml} \mathrm{h}^{-1}$ & 120 \\
\hline
\end{tabular}


history over the last three lockout intervals. The look-up table is designed using fuzzy logic. The bolus size is adjusted according to the button-pressing history over the last two lockout intervals.

The infusate concentrations in Table 3 are different from those in Table 4, because the PCA + FLC system was using the continuous infusion plus small bolus doses. Also, because there is continuous infusion in the PCA + FLC system, the bolus doses can be reduced dramatically compared with those of the conventional PCA system. Therefore the drug concentrations were diluted with saline 5 times more than in the PCA system to prevent the infusion rate being too small for the syringe pump to administer.

\section{Patients and methods}

This study was approved by the National Taiwan University Hospital Ethics Committee. Twenty-five patients were studied who were American Society of Anaesthesiologist physical status 1 or 2 and were undergoing ESWL surgery for calculi in the renal pelvis using a Lithostar lithotriptor.* They were divided into two groups so that our hypothesis could be tested that the amount of alfentanyl drug consumption would be reduced and the patient's satisfaction would be increased when compared with the traditional PCA method.

Group 1 (i.e. 12 patients) was the control group using conventional PCA, with five female and seven male patients, mean age 48 (range 25-71) years and mean weight 66 (range $51-91$ ) kg. The mean duration of control was 33 (range 19-53) min. The mean alfentanyl requirement was 1.36 (range $0.25-2.0$ ) $\mathrm{mg}$. Group 2 (i.e. 13 patients) was the experimental group using the PCA + FLC control technique, with three female and ten male patients, mean age 47 (range 2569) years and mean weight 67 (range 52-80) kg. The mean duration of control was 45 (range 34-86) min. The mean alfentanyl requirement was 0.90 (range $0.32-2.05$ ) $\mathrm{mg}$.

Patients were excluded if they had clinical evidences of severe respiratory problems, history of drug use, alcohol abuse or chronic pain, a positive pregnancy test or calculi outside the renal pelvis.

\subsection{Anaesthetic techniques}

Anaesthetic agents were given by staff members, residents or a nurse anaesthetist with at least one year's experience in anaesthesia. An attending anaesthesiologist involved in the study was always present and responsible for standard monitoring of the patient. Also, one investigator, who designed this monitoring system, was always present and responsible for handling any device or computer malfunction to bring the system back under control by the anaesthesiologist. After the standard monitors (i.e. systolic arterial pressure (SAP), heart rate (HR), saturated oxygen $\left(\mathrm{SpO}_{2}\right)$ and respiration rate (RR)) had been set up, pain intensity was controlled by either conventional PCA or the PCA + FLC method.

\subsection{Computer data input and data output}

The whole system was programmed in the 'Borland $\mathrm{C}++$ ' language. An IBM-compatible notebook was used for collection, display and storage of data. The digital communications were carried out via RS232 serial ports that were interfaced to the Datex Dinamap monitor, a pain driven patient controlled button and an Ohmeda 9000 syringe pump for monitoring clinical signs, such as SAP, HR and the button-pressing profile of the patient, as well as the infusion rate of analgesic, as shown in

*Equipped by Siemens Nixdorf

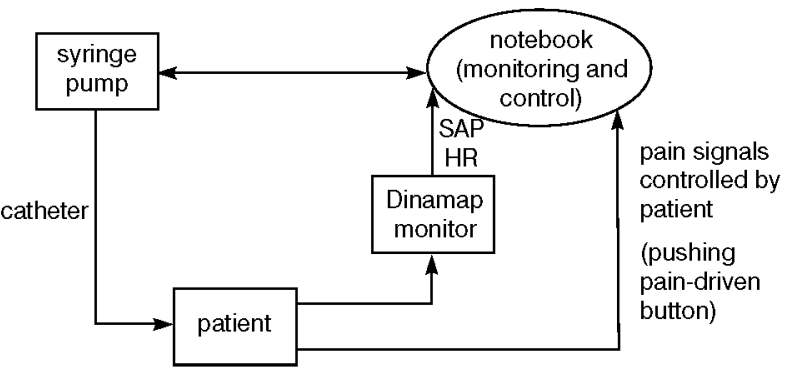

Fig. 3 Flow chart of either PCA or PCA $+F L C$ controller where control system administers alfentanil infusion depending on button-pressing profile of patient

Fig. 3. In addition, the whole system was still under supervision by the anaesthesiologist. The Dinamap monitor was set to provide arterial pressure and heart rate information at 3-5 min intervals. Instruction was given to the patients by an investigator to educate them how to push the button when they felt pain during the EWSL process. Providing a pumping rate from 0.1 to $1200 \mathrm{ml} \mathrm{h}^{-1}$, an Ohmeda 9000 syringe pump was controlled by either the PCA or PCA + FLC controller.

\subsection{Relationship of pain intensity and drug concentration in blood}

Alfentanil is an established drug for the treatment of shock wave-related pain (MONK et al., 1991). Alfentanil is a synthetic opioid with rapid onset and a relatively short duration. These characteristics enable the anaesthetist to adjust the level of opioid analgesia to match the changing surgical stimulus. To facilitate this titration, several computer-controlled infusion pumps based on pharmacokinetic models of alfentanil have been developed (ALVIS et al., 1985; SHAFER et al., 1988; AUSEMS et al., 1983), and this method is also called targetcontrolled infusion (TCI) (CHECKETTs et al., 1998).

The computer-controlled infusion allows the anaesthetist to specify a 'target' alfentanil serum concentration. The infusion pump then administers the appropriate alfentanil dose according to a pharmacokinetic model. However, the performance of a pharmacokinetic model-based administration system is dependent on the parameter values of the model.

MAITRE et al. (1987) performed a population analysis of alfentanil pharmacokinetics with NONMEM, a statistical nonlinear regression program, using data from four published studies. If the drug had been administered using a computercontrolled infusion pump, reasonably reliable and accurate target serum concentrations of alfentanil could be achieved using the pharmacokinetic parameters of SCOTT and STANSKI (1987) in a computer-controlled infusion pump (RAEMER et al., 1990).

However, the classical pharmacokinetic models used in computer-controlled infusion pumps assume instantaneous mixing of the drug in blood, whereas the average recirculation time of blood in the human body is approximately $1 \mathrm{~min}$. Hence, WADA and WARD (1994) proposed a hybrid three-compartment model, as shown in Fig. 4, to overcome this problem. To illustrate the effects of varying the pharmacokinetic study design on the parameter estimates of a three-compartment model, they duplicated the protocols from two clinical pharmacokinetic studies (SCOTT and STANSKI, 1987; CAMU et al., 1982). They simulated peripheral arterial concentrations from the hybrid model over $4 \mathrm{~h}$ and estimated parameters for the threecompartment model using a weighted least squares criterion.

Rate constants, as shown in Table 5, were used in the hybrid model of the WADA and WARD (1994) method, which is thought more suitable to represent the PCA for bolus infusion and 


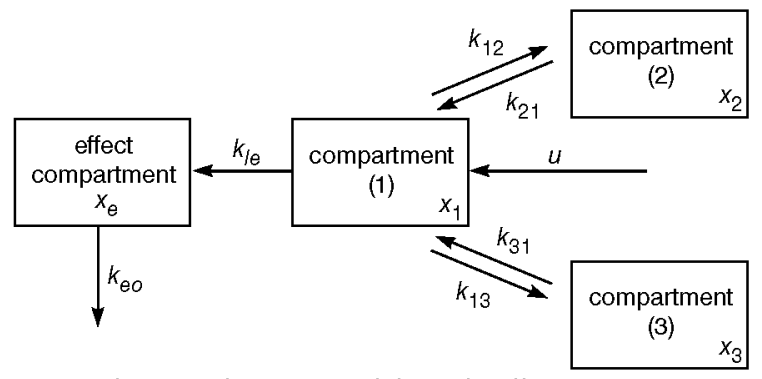

Fig. 4 Pharmacokinetic model and effect compartment model. $\chi_{i}=$ amount of drug in ith compartment; $u=$ amount of drug given in time at any moment in central compartment; and $k_{i j}$ are appropriate intercompartmental first-order rate constants

Table 5 Rate constants of three-compartment model according to WADA and WARD (1994) method

\begin{tabular}{lcc}
\hline $\begin{array}{l}\text { Methods } \\
\text { rate constants, } \min ^{-1}\end{array}$ & PCA & PCA + FLC \\
\hline$k_{10}$ & 0.045 & 0.148 \\
$k_{12}$ & 0.120 & 0.970 \\
$k_{21}$ & 0.089 & 0.460 \\
$k_{13}$ & 0.035 & 0.270 \\
$k_{31}$ & 0.012 & 0.026 \\
\hline
\end{tabular}

PCA + FLC for short infusion. The differences between parameter estimates derived from the short infusion and bolus protocols are most dramatic for $k_{10}, k_{12}, k_{21}$, and $k_{13}$, whether determined in the clinical studies or from the hybrid model. The hybrid model predicts that estimates of $k_{10}$ from short-infusion data could be as little as three times the estimates from bolus data. Similarly, estimates of $k_{12}, k_{21}$, and $k_{13}$ could be five-ten times greater when estimated via a short infusion. Estimates of clearance and $k_{31}$ are not affected as significantly by the different protocols.

SHEINER et al. (1979) produced the findings that the dynamics of the drug effect do not coincide with those of the plasma concentration. To characterise the temporal aspects of the drug effect, a fourth compartment, known as the effect compartment, was introduced. It is connected to the central compartment by a first-order rate constant $k_{1 e}$, whereas the rate constant $k_{e 0}$ characterises the drug dissipation from the effect compartment, as also shown in Fig. 4. Regarding the rate constant of the effect compartment, the half-life of alfentanil is approximate $1 \mathrm{~min}$. Hence, according to the assumption of the first order of the kinetic model during drug distribution in the effect compartment, the rate constant $k_{e 0}$ can be obtained as $0.693 \mathrm{~min}^{-1}$.

To obtain more objective data and a pharmacodynamic model, the count of the buttons pushed by the patient was used to calculate the pain intensity scale according to clinical trials under either the PCA or PCA + FLC method. The methodology of this procedure is as follows.

(i) Record and calculate the drug concentration of the effect compartment according to the pharmacokinetic model, when the patient pushed the button with the PCA method; repeat the recording and calculation for each of the 12 patients

(ii) Record the number of drug demands at a fixed concentration increase; for example, if the increase was chosen as $2.5 \mathrm{ng} \mathrm{ml}^{-1}$, record the number of demands at each $2.5 \mathrm{ng} \mathrm{ml}^{-1}$, starting from $0.0 \mathrm{ng} \mathrm{ml}^{-1}$ until the end of the horizontal axis; in this research, eight different concentration increases were chosen (i.e. 2.5, 3.0, 3.5, 4.0, $4.5,5.0,5.5,6.0 \mathrm{ng} \mathrm{ml}^{-1}$ ) (iii) Normalise the number of drug demands for each concentration interval (i.e. the number of demands in an interval divided by the sum of the number of demands for the entire concentration range); repeat this step for the eight different concentration increases

(iv) Add together the ratio of demands at each concentration interval, from the first patient to the last patient, after normalisation

(v) Multiply the results of procedure (iv) by a scaling factor so that the maximum value equals 100

(vi) Repeat procedures (i)-(v) for 13 patients with the PCA + FLC method.

\section{Results}

Twelve patients using the PCA method and 13 patients using the PCA + FLC method, all undergoing ESWL surgery, were studied. Tables 6 and 7 show the alfentanil drug consumption and the ratio of delivery to demand. According to discussions with anaesthesiologists, the ratio of delivery to demand is strongly related to patient satisfaction. Also, from a clinical view point, the higher the ratio of delivery to demand, the greater the satisfaction of the patient.

The mean (SDs) of drug consumption for the PCA and PCA + FLC methods were 41.3 (18.0) and 18.7 (9.2) $\mu \mathrm{g} \cdot \mathrm{kg}^{-1} \mathrm{~h}^{-1}$, respectively. The ratios of delivery to demand for the PCA and PCA + FLC methods were $60 \%$ and $82 \%$. Therefore the results have shown that the PCA + FLC method is more effective than the PCA method. Not only is the amount of drug consumed smaller than that for the PCA method, but also its ratio of delivery to demand is higher than that for the PCA method.

Furthermore, the relationship between the pain intensity scale and drug concentration in the effect compartment for eight different drug concentration increases is shown in Figs 5 and 6 for the PCA method and the PCA + FLC method, respectively. To obtain more objective data, the eight different drug concentration increases were chosen (i.e. 2.5, 3.0, 3.5, 4.0, 4.5, 5.0, 5.5, $6.0 \mathrm{ng} \mathrm{ml}^{-1}$ ). The larger the drug concentration increases chosen, the fewer data points represented. The numbers of drug demands were obtained as shown in Figs $5 a-h$ and Figs $6 a-h$.

If the maximum of the pain intensity scale is defined as $100 \%$, the acceptable pain intensity scale of the patient is approximately $30 \%$ according to the clinical experience of the anaesthesiologist. Table 8 shows that the percentage of the pain intensity scale below $30 \%$ is $62 \%$ for PCA + FLC, in contrast to $44 \%$ for $\mathrm{PCA}$. The results tell us that the pain intensity scale of the PCA + FLC method is significantly lower than that of the PCA method, which is consistent with the greater satisfaction of the patient, as the drug consumption and the ratio of delivery to demand indicate.

\section{Discussion}

The use of a background infusion in PCA is the subject of some disagreement, although it is not generally used (OWEN et al., 1989; ZACHARIAS et al., 1990), because most background infusion in PCA is set at a constant infusion rate, according to the anaesthesiologist's experience, and does not change when the patient pushes the button. In this study, background infusion was used as well.

We utilised the fuzzy logic PCA algorithm to relieve intraoperative pain. The algorithm adjusts both the bolus dose and the background infusion rate of analgesic, depending on how often 
Table 6 Drug consumption of alfentanil by patients undergoing ESWL surgery with PCA method and PCA $+F L C$ method (units are $\mu \mathrm{g} \cdot \mathrm{kg}^{-1} \mathrm{~h}^{-1}$ )

\begin{tabular}{|c|c|c|c|c|c|c|c|c|c|c|c|c|c|c|}
\hline $\begin{array}{l}\text { Patient number system } \\
\text { PCA }\end{array}$ & $\begin{array}{c}1 \\
45.6\end{array}$ & $\begin{array}{c}2 \\
28.3\end{array}$ & $\begin{array}{c}3 \\
56.9\end{array}$ & $\begin{array}{c}4 \\
39.1\end{array}$ & $\begin{array}{c}5 \\
30.9\end{array}$ & $\begin{array}{c}6 \\
44.6\end{array}$ & $\begin{array}{c}7 \\
60.4\end{array}$ & $\begin{array}{c}8 \\
75.9\end{array}$ & $\begin{array}{l}9 \\
5.9\end{array}$ & $\begin{array}{c}10 \\
27.9\end{array}$ & $\begin{array}{c}11 \\
38.3\end{array}$ & $\begin{array}{c}12 \\
42.3\end{array}$ & & $\begin{array}{l}\text { Mean } \pm \text { SD } \\
41.3 \pm 18.0\end{array}$ \\
\hline Patient number system & 13 & 14 & 15 & 16 & 17 & 18 & 19 & 20 & 21 & 22 & 23 & 24 & 25 & Mean \pm SD \\
\hline
\end{tabular}

Table 7 Ratio of delivery to demand for patients undergoing ESWL surgery with PCA method and PCA + FLC method; 1 means that patient did not push any button, but we assume ratio is $100 \%$

\begin{tabular}{|c|c|c|c|c|c|c|c|c|c|c|c|c|c|c|}
\hline $\begin{array}{l}\text { Patient number system } \\
\text { PCA }\end{array}$ & $\begin{array}{c}1 \\
3 / 8\end{array}$ & $\begin{array}{c}2 \\
3 / 4\end{array}$ & $\begin{array}{c}3 \\
8 / 8\end{array}$ & $\begin{array}{c}4 \\
6 / 8\end{array}$ & $\begin{array}{c}5 \\
6 / 9\end{array}$ & $\begin{array}{c}6 \\
7 / 11\end{array}$ & $\begin{array}{c}7 \\
6 / 31\end{array}$ & $\begin{array}{c}8 \\
5 / 24\end{array}$ & $\begin{array}{l}9 \\
1\end{array}$ & $\begin{array}{c}10 \\
7 / 13\end{array}$ & $\begin{array}{c}11 \\
8 / 18\end{array}$ & $\begin{array}{c}12 \\
9 / 14\end{array}$ & & $\begin{array}{l}\text { Mean } \\
60 \%\end{array}$ \\
\hline $\begin{array}{l}\text { Patient number system } \\
\text { PCA + FLC }\end{array}$ & $\begin{array}{c}13 \\
10 / 12\end{array}$ & $\begin{array}{l}14 \\
3 / 3\end{array}$ & $\begin{array}{l}15 \\
6 / 8\end{array}$ & $\begin{array}{c}16 \\
1\end{array}$ & $\begin{array}{l}17 \\
6 / 7\end{array}$ & $\begin{array}{l}18 \\
2 / 5\end{array}$ & $\begin{array}{l}19 \\
4 / 4\end{array}$ & $\begin{array}{l}20 \\
8 / 8\end{array}$ & $\begin{array}{c}21 \\
8 / 10\end{array}$ & $\begin{array}{l}22 \\
4 / 6\end{array}$ & $\begin{array}{l}23 \\
4 / 4\end{array}$ & $\begin{array}{l}24 \\
4 / 5\end{array}$ & $\begin{array}{c}25 \\
14 / 23\end{array}$ & $\begin{array}{c}\text { Mean } \\
82 \%\end{array}$ \\
\hline
\end{tabular}

the patient pushes the button. Fuzzy logic gives user-friendly interfacing with humans. In practice, a precise model may not exist for biological systems, or it may be too difficult to model. In most cases, fuzzy logic is considered to be an ideal tool, as human minds work from approximate data, extract meaningful information and produce crisp solutions (MAHFOUF et al., 2001). The purpose of this adjustment of both the bolus dose and the background infusion rate of analgesic was to overcome the huge variety in patients' drug requirements for adequate analgesia.

Although we did not take a blood sample to analyse, Fig. 7 is a predicting curve of the drug concentration profile and shows that serum alfentanil drug concentration can be achieved as closely as the analgesia level when the PCA + FLC method is used. However, the PCA method shows serum alfentanil drug concentration can vary very widely between pain and sedation level. That is why the PCA still produces some clinical side effects, such as nausea, dizziness, and vomiting. Also, in our study, PCA + FLC patients had acceptable pain intensity at $62 \%$, compared with at $44 \%$ in conventional PCA. It means that the PCA + FLC method is closer to an ideal curve of analgesic drug therapy.
In this study, the means (SDs) of drug consumption of the PCA and PCA + FLC methods were 41.3 (18.0) and 18.7 (9.2) $\mu \mathrm{g} \cdot \mathrm{kg}^{-1} \mathbf{h}^{-1}$, respectively. PCA + FLC patients consumed $45 \%$ less drug than PCA patients. From closed-loop control theory, the PCA controller is like an on-off controller. The controller does not use too much effort controlling the drug administration. When the alfentanil drug concentration has been eliminated greatly from the blood, the patient starts to feel pain and pushes the button. As the alfentanil drug concentration in the blood is low (i.e. far below the threshold of the pain level), it needs more drug to be injected into the blood. However, the PCA + FLC controller is like a proportional-integral-derivative (PID) controller but always better. It adjusts the continuous infusions and the bolus size as well, to achieve the threshold of the pain level for each patient. When the patient starts to feel pain and pushes the button, the alfentanil drug concentration in the blood does not drop far below the threshold of the pain level as it does with the PCA controller. Because the alfentanil drug concentration in the blood is not low, it therefore needs less drug injected into the blood.
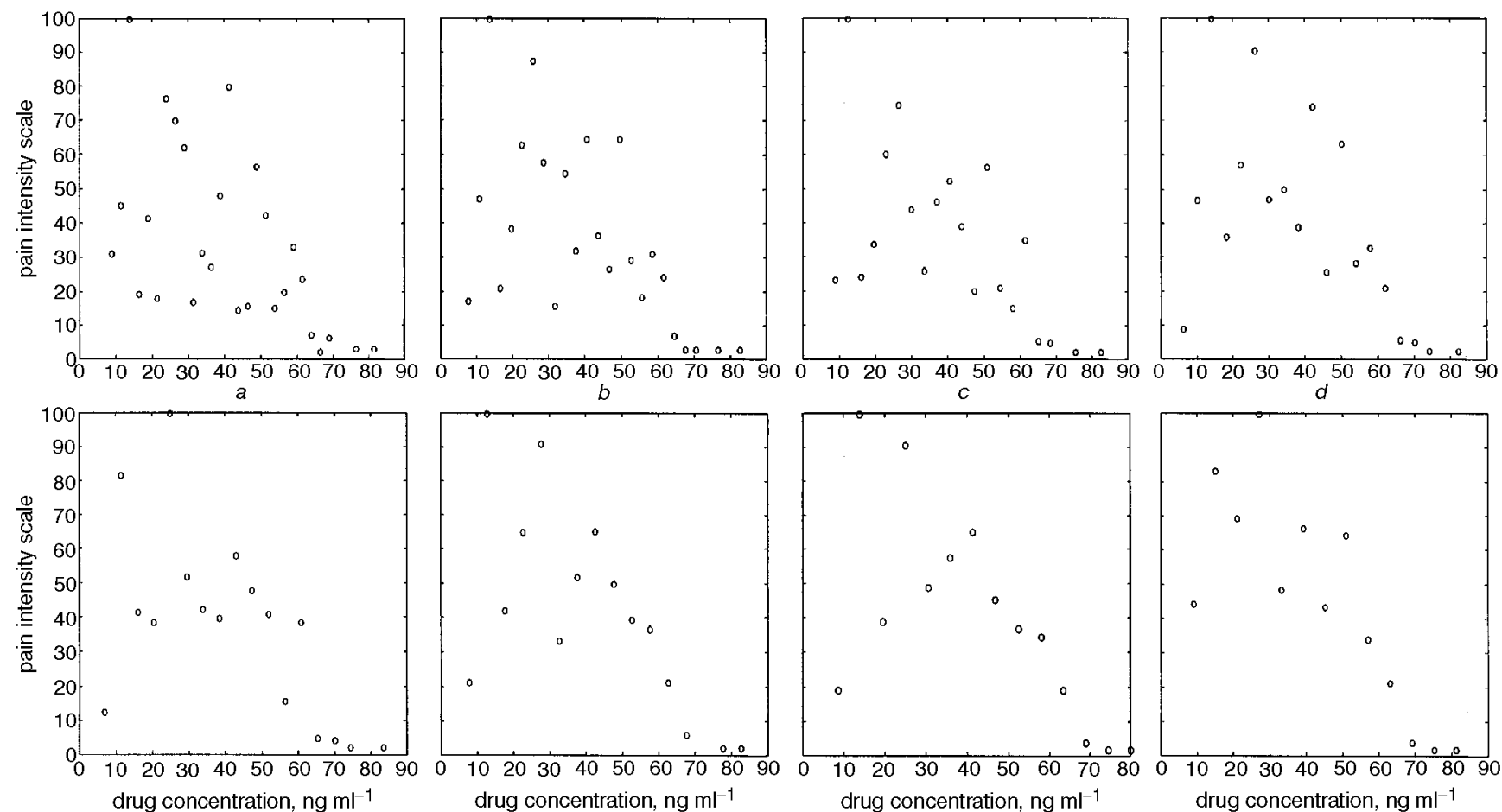

drug concentration, $\mathrm{ng} \mathrm{m}^{-1}$

drug concentration, $\mathrm{ng} \mathrm{ml}^{-1}$

$$
\text { e }
$$

$$
f
$$

drug concentration, $\mathrm{ng} \mathrm{ml}^{-1}$

$g$ drug concentration, $\mathrm{ng} \mathrm{ml}^{-1}$

$$
h
$$

Fig. 5 Relationship between pain intensity scale and drug concentration in effect compartment for different drug concentration intervals using PCA method: (a) $2.5 \mathrm{ng} \mathrm{ml}^{-1}$; (b) $3.0 \mathrm{ng} \mathrm{ml}^{-1}$; (c) $3.5 \mathrm{ng} \mathrm{ml}^{-1}$;(d) $4.0 \mathrm{ng} \mathrm{ml}^{-1}$; (e) $4.5 \mathrm{ng} \mathrm{ml}^{-1}$; (f) $5.0 \mathrm{ng} \mathrm{ml}^{-1}$; (g) $5.5 \mathrm{ng} \mathrm{ml}^{-1}$; (h) $6.0 \mathrm{ng} \mathrm{ml}^{-1}$ 

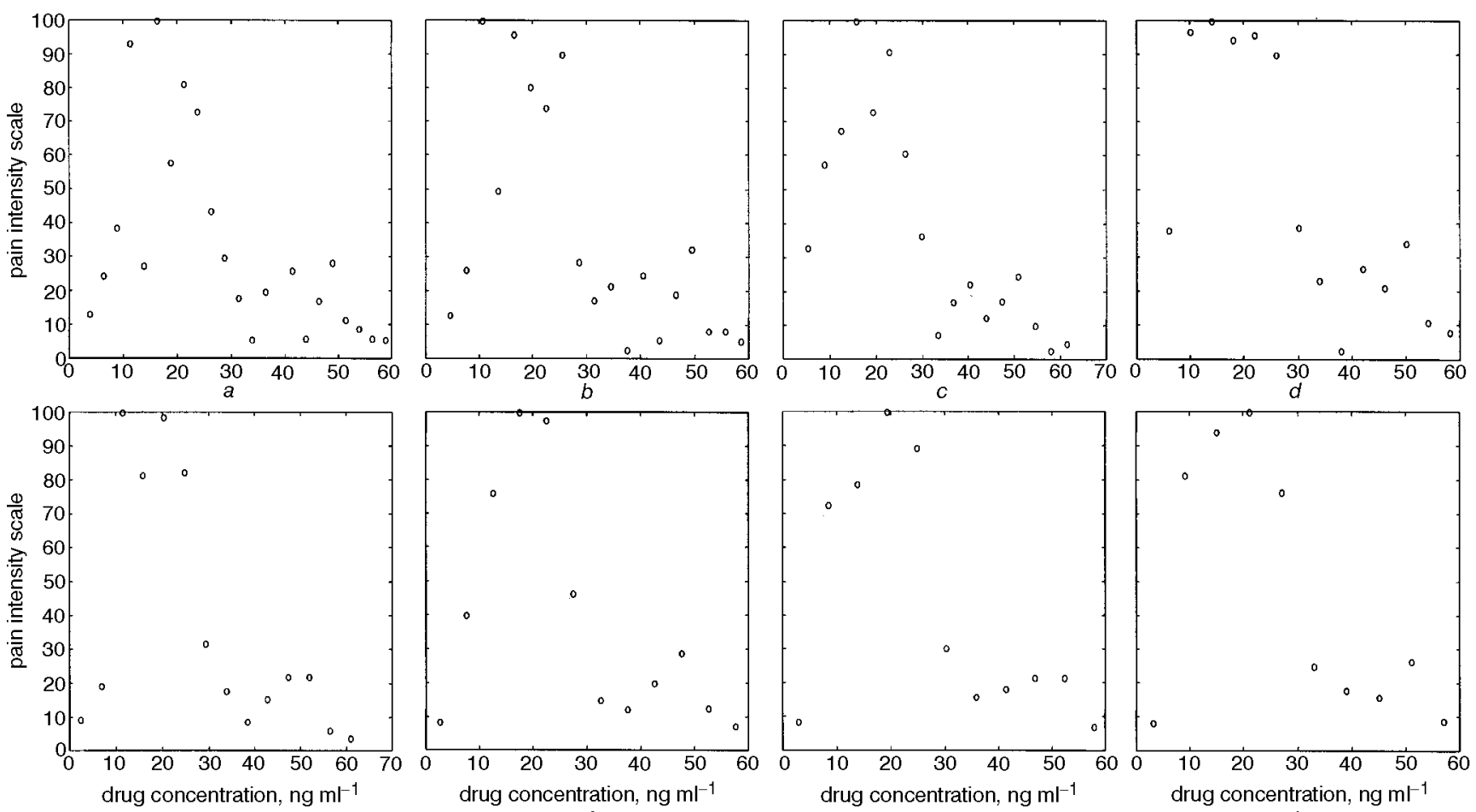

$f$

$g$

$h$

Fig. 6 Relationship between pain intensity scale and drug concentration in effect compartment for different drug concentration intervals using

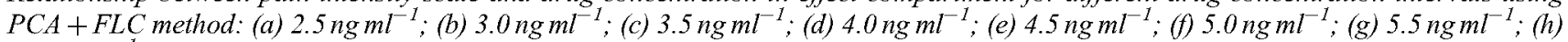
$6.0 n g m l^{-1}$

This is the first paper using fuzzy logic control applied to clinical pain therapy. There is only one previous paper using fuzzy logic control to simulate post-operative pain (CAROLlo et al., 1993). This is also the first use of FLC in PCA. It is quite similar to previous FLC methods, except that the rule-base is totally different from other FLC methods. In this paper, the rule-base, which can play a major part in this system, was generated from discussions with anaesthesiologists. However, it is still difficult to standardise how to co-operate and discuss with clinical physicians to generate this fuzzy rulebase. Hence, more research will have to be carried out, especially in the area of self-tuning rules.

There are many publications (SHIEH et al., 1999; MAHFOUF et al., 2001) investigating this area of self-organising fuzzy logic control (SOFLC). It can provide an adaptive rule-learning capability to complement a fuzzy logic control strategy. Not only can the rule-base be generated gradually according to a not very precise rule-base, but also it can be from zero knowledge. Hence, the SOFLC will be designed to modify the fuzzy rulebase so that inter-patient variations can be taken care of. Also, it will approach more accurate control of pain, although pain feeling is very subjective.

The fuzzy logic controller was simulated to assess design variables according to the simulation of the button-pressing profile of the patient. This off-line simulation can test how good the selection of the triangle shapes is for membership functions, and how good the selection of the number of levels is for inputs and outputs. However, this off-line simulation is still an open-loop system. To perform closed-loop simulation, a patient model of the pain intensity scale will be built in the following stage.

Artificial neural networks (ANNs) offer a better possibility of rapid knowledge acquisition using their self-organising learning properties. They have the ability to learn in those cases where it is possible to specify the inputs and outputs but difficult to define the relationship between them. They are also tolerant of noise in the input data and find it easy to cope with non-linear systems. These attributes of ANNs are suitable for the domain of
Table 8 Percentage of pain intensity scale below 30 with $P C A$ method and PCA + FLC method

\begin{tabular}{lcc}
\hline Concentration increase, $\mathrm{ng} \mathrm{ml}^{-1}$ & PCA, $\%$ & PCA + FLC, $\%$ \\
\hline 2.5 & 63 & 68 \\
3.0 & 58 & 68 \\
3.5 & 50 & 59 \\
4.0 & 47 & 50 \\
4.5 & 35 & 71 \\
5.0 & 33 & 58 \\
5.5 & 36 & 64 \\
6.0 & 31 & 60 \\
Mean & 44 & 62 \\
\hline
\end{tabular}

anaesthesia (SHIEH et al., 2000) and pain intensity, because the relationships between clinical signs are not clear and are highly non-linear.

Also, an Elman network will be considered in the modelling to overcome time problems during the administration of drugs.

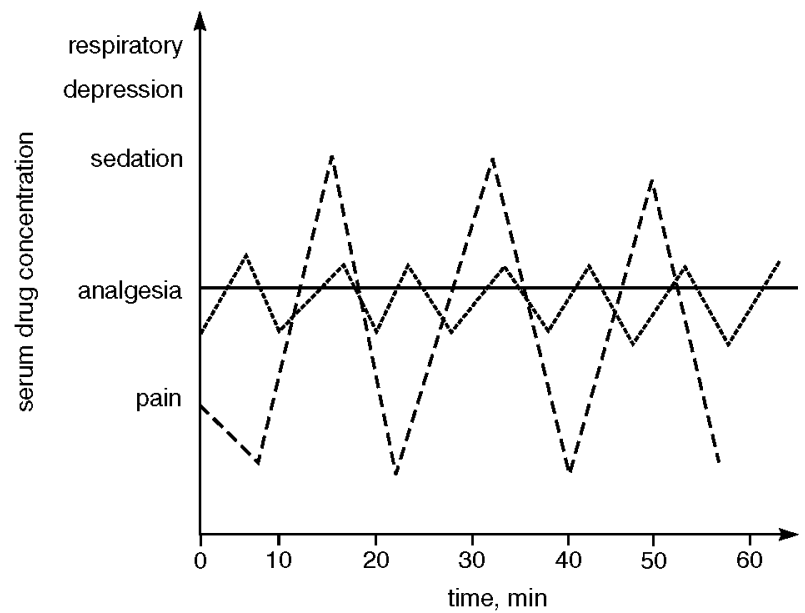

Fig. 7 Serum drug concentration profile under analgesic drug therapy. (- - Ideal curve; (...) PCA + FLC method; (- - -) PCA method 
However, the network must first be trained. To build the patient model more completely using ANNs, further clinical monitoring data need to be collected continuously in the following stage.

\section{Conclusions}

In this preliminary study of the control of pain intensity, we have demonstrated the clinical utility of a simplified fuzzy logic PCA algorithm approach to alfentanil-induced pain relief in extracorporeal shock-wave lithotripsy. The current research can now be expanded to encompass alternative analgesic techniques and different analgesic drugs (e.g. morphine, fentanyl). In addition, this general fuzzy logic PCA algorithm could be expanded to include other analgesia applications, such as prostate enlargement therapy in operating rooms, post-operative analgesia in recovery rooms and wards, and even more complex multivariable control problems, such as the treatment of pain in intensive care units and cancer pain at home.

Acknowledgments - The authors wish to thank the National Health Research Institute (NHRI) in Taiwan (Grant number NHRI-GT-EX89) for supporting this research. The work was carried out at the National Taiwan University Hospital.

\section{References}

Alvis, J. M., Reves, J. G., Govier, A. V., Menkhaus, P. G., Henling, C. E., Spain, J. A., and Bradley, E. (1985): 'Computer-assisted continuous infusion of fentabyl during cardiac anesthesia', Anesthesiology, 63, pp. 41-49

Ausems, M. E., Hug, C. C. Jr., and DE LANGe, S. (1983): 'Variable rate infusion of alfentanil as a supplement to nitrous oxide anesthesia foe general surgery', Anesth. Analg., 62, pp. 1217-1225

BraAe, M., and RutheRForD, D. A. (1978): 'Fuzzy relation in a control setting', Kybernetes, 7, pp. 185-188

CAMU, F., GePTS, E., RuCQuoI, M., and HEYKants, J. (1982): 'Pharmacokinetics of alfentanil in man' Anesth. Analg., 61, pp. 657-661

CARollo, A., Tobar, A., and Hernandez, C. (1993): 'A rule-based postoperative pain controller: simulation results', Int. J. Biomed. Comput., 33, pp. 267-276

Checketts, M. R., Gilhooly, C. J., and KenNy, G. N. C. (1998): 'Patient-maintained analgesia with target-controlled alfentanil infusion after cardiac surgery: a comparison with morphine PCA', $B r . J$. Anaesthes., 80, pp. 748-751

DomBI, J. (1990): 'Membership function as an evaluation', Fuzzy Sets \& Syst., 35, pp. 1-21

KatZ, J., JaCkson, M., KaVAnagh, B. P., and SANDler, A. N. (1996): 'Acute pain after thoracic surgery predicts long-term post-thoracotomy pain', Clin. J. Pain., 12, pp. 50-55

KosKo, B. (1991): 'Neural networks and fuzzy systems' (Prentice-Hall International, Inc., Singapore, 1991)

KOUATLI, I. M., and JONES, B. (1991): 'An improved design procedure for fuzzy control systems', Int. J. Mach. Tools Manufact., 31, pp. $107-122$

LI, Y. F., and LAU, C. C. (1989): 'Development of fuzzy algorithms for servo systems', IEEE Control Syst. Mag., 9, pp. 65-72

LinkENS, D. A., and MAHFOUF, M. (1988): 'Fuzzy logic knowledgebased control for muscle relaxation anaesthesia'. IFAC Symposium on Modelling and Control in Medicine, Venice, pp. 185-190

LINKENS, D. A., and ABBOD, M. F. (1992): 'Self-organizing fuzzy logic control and the selection of its scaling factors', Trans. Ins. Meas. Control, 14, pp. 114-125

Love, D. R., OWEN, H., IlsLey, A. H., Plummer, J. L., HawkIns, R. M., and MORRISON, A. (1996): 'A comparison of variable-dose patientcontrolled analgesia with fixed-dose patient-controlled analgesia', Anesth. Analg., 83, pp. 1060-1064

Lynch, E. P., Lazor, M. A., Gellis, J. E., Orav, J., Goldman, L., and Marcantonio, R. (1998): 'The impact of postoperative pain on the development of postoperative delirium', Anesth. Analg., 86, pp. $781-785$
MAHFoUf, M., ABBoD, M. F., and LinKENS, D. A. (2001): 'A survey of fuzzy logic monitoring and control utilization in medicine', Artif. Intell. Med., 21, pp. 27-42

Maitre, P. O., Vozeh, S., Heykants, J., Thomson, D. A., and STANSKI, D. R. (1987): 'Population pharmacokinetics of Alfentanil: the average dos-plasma concentration relationship and interindividual variability in patient', Anesthesiol., 66, pp. 3-12

Mason, D. G., Ross, J. J., Edwards, N. D., Linkens, D. A., and REILLY, C. S. (1996): 'Performance assessment of a fuzzy controller for atracurium-induced neuromuscular block', Br. J. Anaesth., 76, pp. $396-400$

MAsON, D. G., LINKENS, D. A., Edwards, N. D., and ReILly, C. S. (1997a): 'Development of a portable closed-loop atracurium infusion systems: systems methodology and safety issues', Int. J. Clin. Monit. Comput., 13, pp. 243-252

Mason, D. G., Ross, J. J., Edwards, N. D., Linkens, D. A., and REILLY, C. S. (1997b): 'Self-learning fuzzy control of atracuriuminduced neuromuscular block during surgery', Med. Biol. Eng. Comput., 35, pp. 498-503

MONK, T. G., RATER, J. M., and White, P. F. (1991): 'Comparison of alfentanil and ketamine infusions in combination with midazolam for outpatient lithotripsy', Anesthesiology, 74, p. 1023

MonK, T. G., Ding, Y., White, P. F., Albala, D. M., and Clayman, R. V. (1994): 'Effect of topical eutectic mixture of local anesthetic of pain response and analgesic requirement during lithotrips procedures', Anesth. Anal., 79, p. 506

Owen, H., Szekely, S. M., Plummer, J. L., Cushnie, J. M., and MATHER, L. E. (1989): 'Variable of patient-controlled analgesia: concurrent infusion', Anaesthesia, 44, pp. 11-13

Owen, H., Plummer, J. L., Ilsley, A., HaWkins, R., ARFEen, Z., and TORDOFF, K. (1995): 'Variable-dose patient-controlled analgesia: a preliminary report', Anaesthesia, 50, pp. $855-857$

RaEmer, D. B., Buschman, A., Varvel, J. R., Philip, B. K., JOHNSON, M. D., STEIN, D. A., and SHAFER, S. L. (1990): 'The prospective use of population pharmacokineics in a computerdriven infusion system for alfentanial', Anesthesiol., 73, pp. 66-72

Ross, J. J., Mason, D. G., Linkens, D. A., and Edwards, N. D. (1997): 'Self-learning fuzzy logic control of neuromuscular block', Br. J. Anaesth., 78, pp. 412-415

Schellng, G., Weber, W., Sackmann, M., and Peter, K. (1989): 'Pain control during extracorporeal shock wave lithotripsy of gallstones by titrated alfentanil infusion', Anesthesiol., 70, p. 1022

Schelling, G., Weber, W., Mendl, G., Braun, H., and CullmanN, H. (1996): 'Patient controlled analgesia for shock wave lithotripsy: the effect of self-administered alfentanil on pain intensity and drug requirement', $J$. Urol., 155 , pp. 43-47

ScotT, J. C., and STANSKI, D. R. (1987): 'Decreased fentanyl and alfentanil dose requirements with age. A simultaneous pharmacokunetic and pharmacodynamic evaluation', J. Pharmacol. Exp. Ther, 240, pp. 159-166

Shafer, S. L., Siegel, L. C., CoOKe, J. E., and ScotT, J. C. (1988): 'Testing computer-controlled infusion pumps by simulation', Anesthesiol., 68, pp. 261-266

SHEINER, L. B., STANSKI, D. R., VOZEH, S., MiLlER, R. D., and HAM, J. (1979): 'Simultaneous modeling of pharmacokinetics and pharmacodynamics: application to d-tubocurarine', Clin. Pharmacol. Ther., 25, pp.358-361

ShieH, J. S., Chang, L. W., FAN, S. Z., and LiU, C. C. (1996): 'Hierarchical monitoring and fuzzy logic control of muscle relaxation', Biomed. Eng. Appl. Basis Comm., 8, pp. 392-402

Shieh, J. S., Chang, L. W., Fan, S. Z., and LiU, C. C. (1997): 'Hierarchical monitoring and fuzzy logic control of neuromuscular block with mivacurium', Biomed. Eng. Appl. Basis Comm., 9, pp. 261-267

SHIEH, J. S., LinKENS, D. A., and PEACOCK, J. E. (1999): 'Hierarchical rule-base and self-organizing fuzzy logic control for depth of anaesthesia', IEEE Trans. Syst. Man Cybern. C, Appl. Rev., 29(1), pp. $98-109$

ShIEH, J. S., ChOU, Q. F., and Fan, S. Z. (2000): 'Modelling of bispectral index using artificial neural networks during inhalational anaesthesia', Biomed. Eng. Appl. Basis Comm., 12, pp. 44-51

WADA, D. R., and WARD, D. S. (1994): 'The hybrid model: a new pharmacokinetic model for computer-controlled infusion pumps', IEEE Trans. Biomed. Eng., 41, pp. 134-141 
Woodhouse, A., and MATHER, L. E. (1997): 'The influence of age upon opioid analgesic use in the patient-controlled analgesia (PCA) environment', Anaesthesia, 52, pp. 949-955

YING, H., ShePPARD, L., and TuCKER, D. (1988): 'Expert-systemsbased fuzzy control of arterial pressure by drug infusion', Med. Progr. Through Technol., 13, pp. 672-683

ZaCharias, M., Pfeifer, M. V., and Herbison, P. (1990): 'Comparison of two methods of intravenous administration of morphine for postoperative pain relief', Anaesth. Intens. Care, 18, pp. 205-209

ZADEH, L. A. (1965): 'Fuzzy sets', Inform. Control, 8, pp. 338-353

\section{Authors' biographies}

JIANN-SHING SHIEH received his $\mathrm{PhD}$ in Automatic Control and Systems Engineering from the University of Sheffield, UK, in 1995.

$\mathrm{He}$ is an Assistant Professor in the Department of Mechanical Engineering at the University of Yuan Ze, Taoyuan, Taiwan. His current research interests include learning systems, fuzzy control, artificial intelligence, control of anaesthesia, and pain model and control.

LIANG-WEY CHANG received his $\mathrm{PhD}$ in Mechanical Engineering from Purdue University, West Lafayette, IN, USA, in 1984 . He is an
Associate Professor in the Institute of Biomedical Engineering at National Taiwan University. His research lies in biomechanical engineering and particularly the design and control of orthotic and therapeutic devices.

MIN-SHEN WANG graduated from the National Taiwan University and received his Master in Mechanical Engineering in 1998.

YONG-PING WANG is an anaesthesiologist at the National Taiwan University Hospital. He holds an MD from the College of Medicine, National Taiwan University.

YEE-PIEN YANG is a Professor in the Department of Mechanical Engineering at National Taiwan University. He obtained his $\mathrm{PhD}$ in Mechanical Engineering from UCLA, USA, in 1988. His research projects cover various aspects of the design and control of mechanical systems.

WEI-ZEN SUN has an MD from the College of Medicine, National Taiwan University. He currently serves as the Chairman of the Department of Anaesthesiology at the National Taiwan University Hospital. 